042 NON-PEER REVIEWED:

\title{
Service-Learning Education Integrated Design Education Through a Design- Build Focus
}

Michael Chan

108- 121

\author{
Different from the conventional design-built projects, the \\ service-learning educational model represents a student \\ led community driven education process. This photos es- \\ say delivers evidence, spanning 15 years and various con- \\ texts, demonstrating the impact of service learning and \\ its dependency on cross-disciplinary skills. Beyond the \\ social value, service learning fosters a series of interper- \\ sonal and professional relationships, amplifying skills and \\ education value outside of the classroom.
}

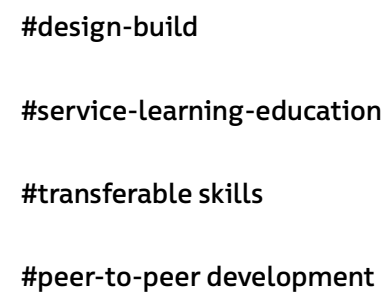




\section{Service Learning}

The Service-Learning educational model represents an alternative to design education in the context of the digital paradigm. Mechanising design-build projects, the emphasis of the service-learning model shifts attention away from the tutor driven model to a student led process. In addition, the model represents an open and cross-discipline model, open to all students of all academic backgrounds and skills to co-design and co-develop build work. This has facilitated a range of tangential projects that formalise cooperative projects between industry, communities and students.

With the ultimate emphasis to enhance the living conditions of under-developed areas and marginalised communities, service learning aims at community enrichment, with a specific focus on the development of village centres and eco-facilities. Six goals outline the service-learning project. First, to provide university students a real-life experience of executing a service project which has a direct impact on social life. Secondly, to respect, appreciate, and preserve the local culture and environment, and to promulgate the concept of sustainability. Third, to encourage students to work with professionals for improving the lives of underprivileged communities by initiating and implementing design and building projects. Fourth, to foster better communication, mutual understanding, and engagement between students and villagers, to develop interpersonal skills and build community links among them. Fifth, to transfer practical building skills and knowledge of materials that promulgated the concept of sustainability, with locally available and sustainable materials, utilizing local wisdom and green building concepts. And finally, to empower villagers with transferable skills to develop and expand their own communities.

Working on the development, design and construction of a real-life project, students work closely with the professional and experts such as architects, engineers, surveyors, and local carpenters to complete the project to a range of standards. Supported by professional and academic staff from relevant faculties and department, students were guided for the entire process, developing knowledge that is transferred through peer-to-peer learning, applying knowledge beyond classroom teaching.

With a longevity of more than fifteen years, the Wu Zhi Qiao Project - PolyU Chapter and School of Design Service-Learning Programme has successfully completed over twenty-three projects in nineteen villages. Including fourteen footbridges, six village centres, eight village facilities and a series of community enrichment projects in seven provinces in China and two Prefectures in Japan. The project has impacted over 2000 University Students from Hong Kong, The Chinese Mainland, and overseas to benefit in the with collaborative stagiest of more than 80,000 Chinese villagers. 


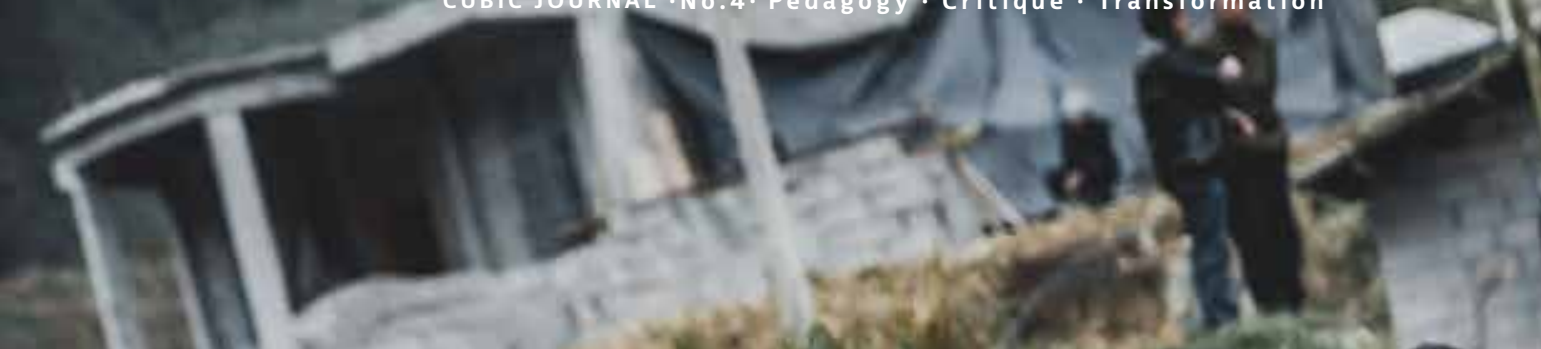
$6,3 \times$

watsin $x$

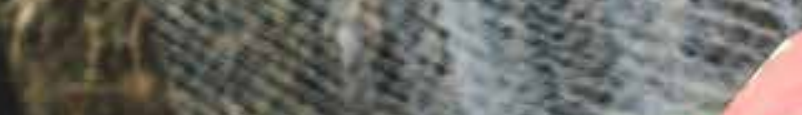
(10) $\Rightarrow 1$ sers $-$ vish 3 EN 1 (x) as

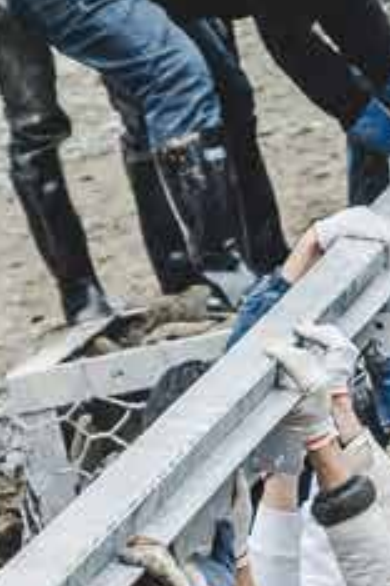

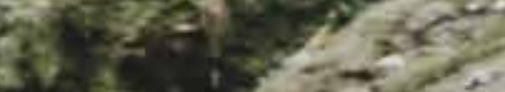
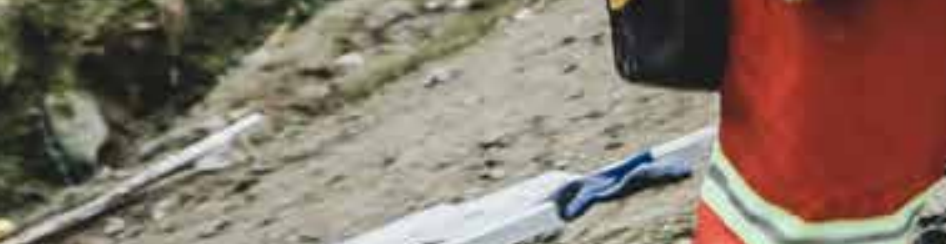

$\int_{0}$

8

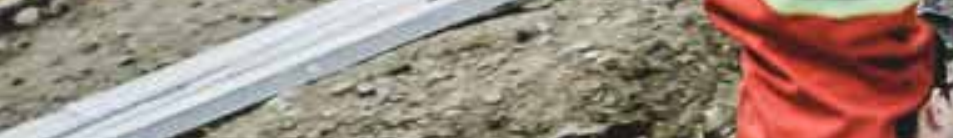

$+1$

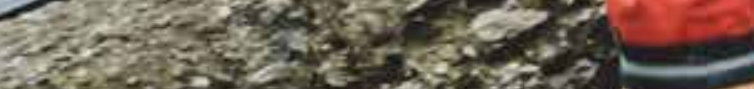

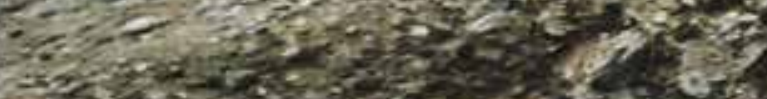

W

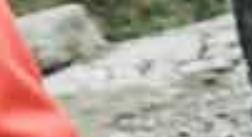

$-5 \sqrt{6}$ S. (8) 
Michael Chan - Service-Learning Education Integrated Design Education Through a Design-Build Focus

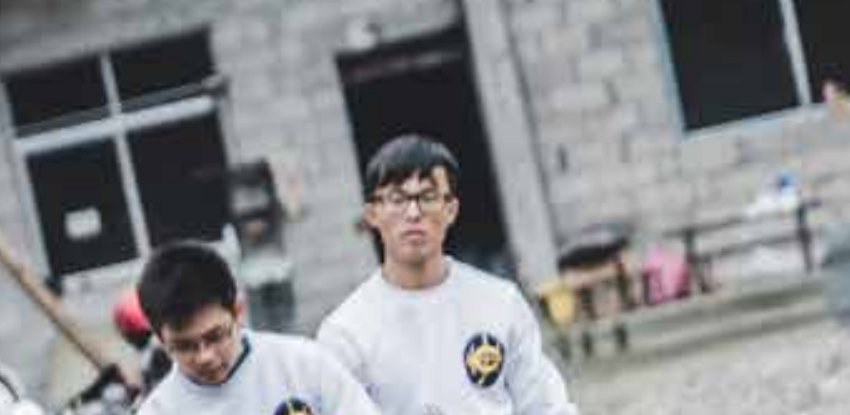

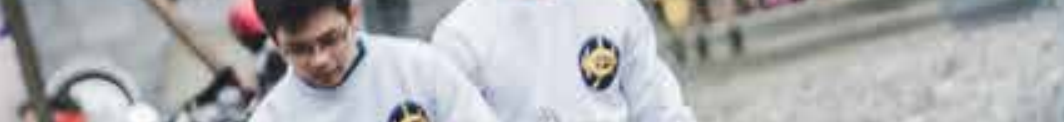

MAñy. - $4+1$ 30

a.

$-x^{2}$

$6012 x$

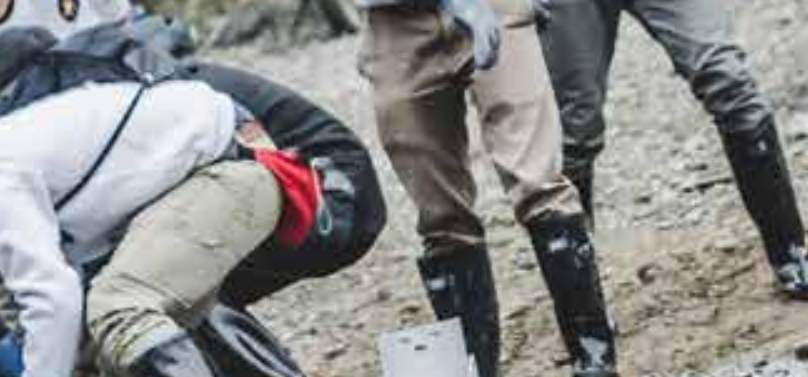

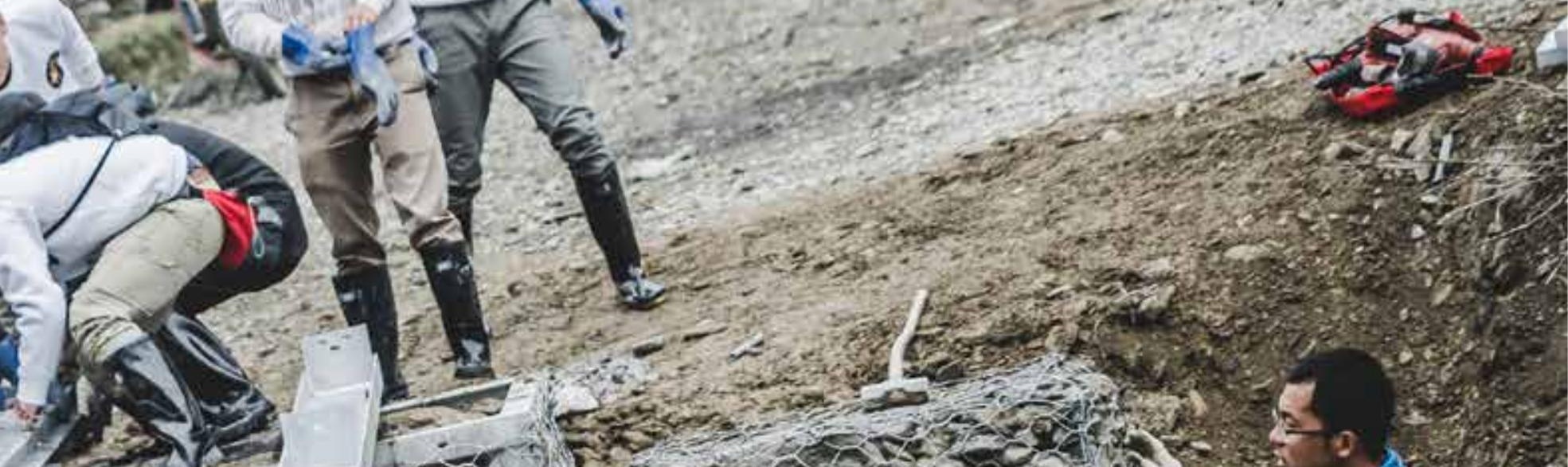
. 12. 16

(2)

25

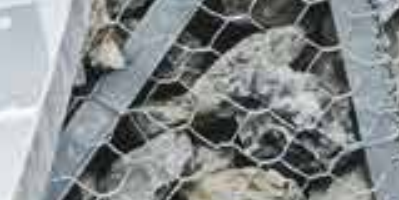

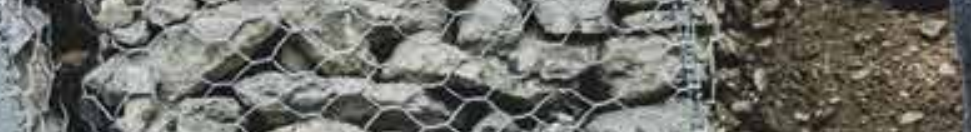

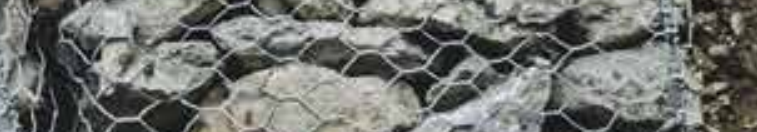

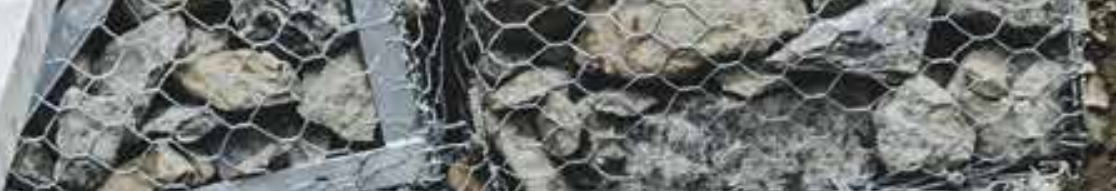

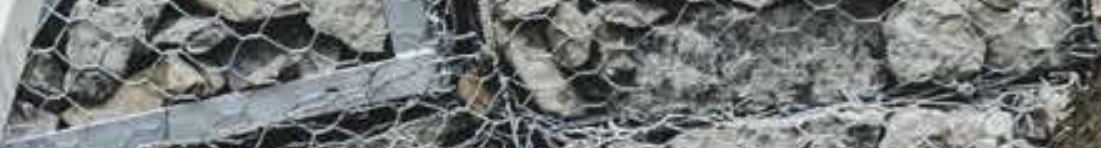
ar rer

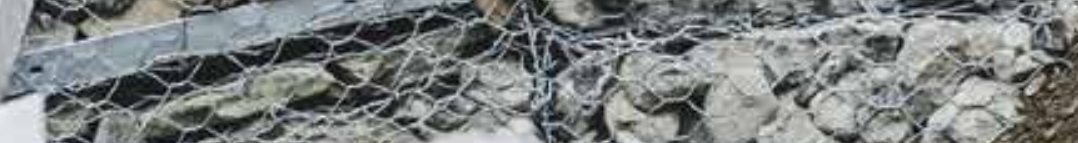

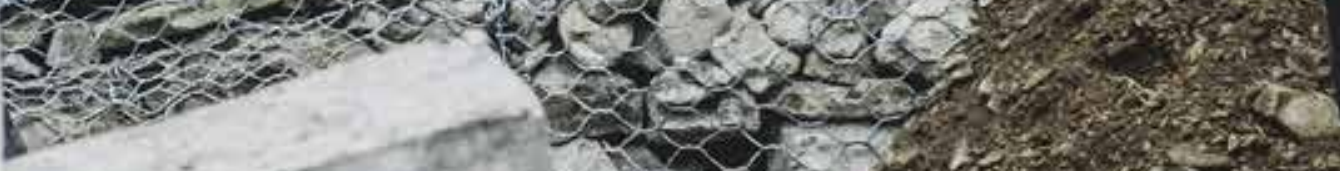

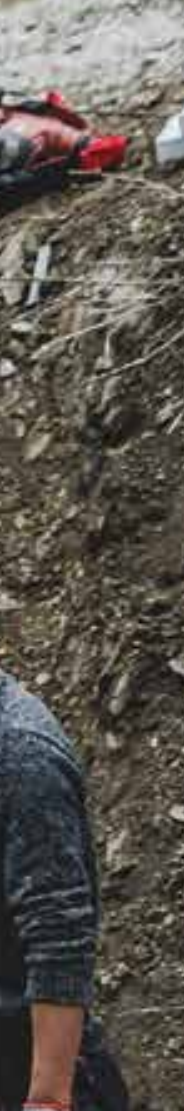
Dit $\frac{6}{2}$
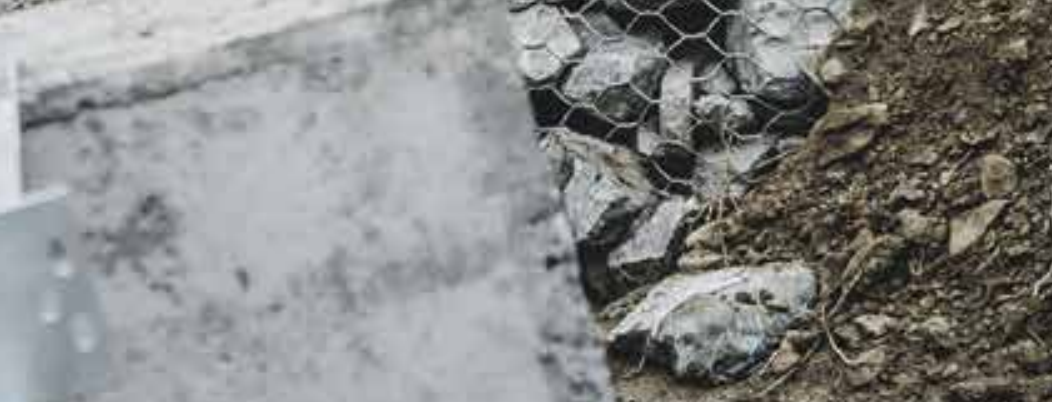

$\frac{15}{y-2}+1=$ 1. 35

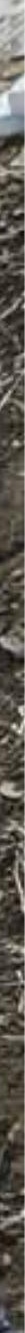




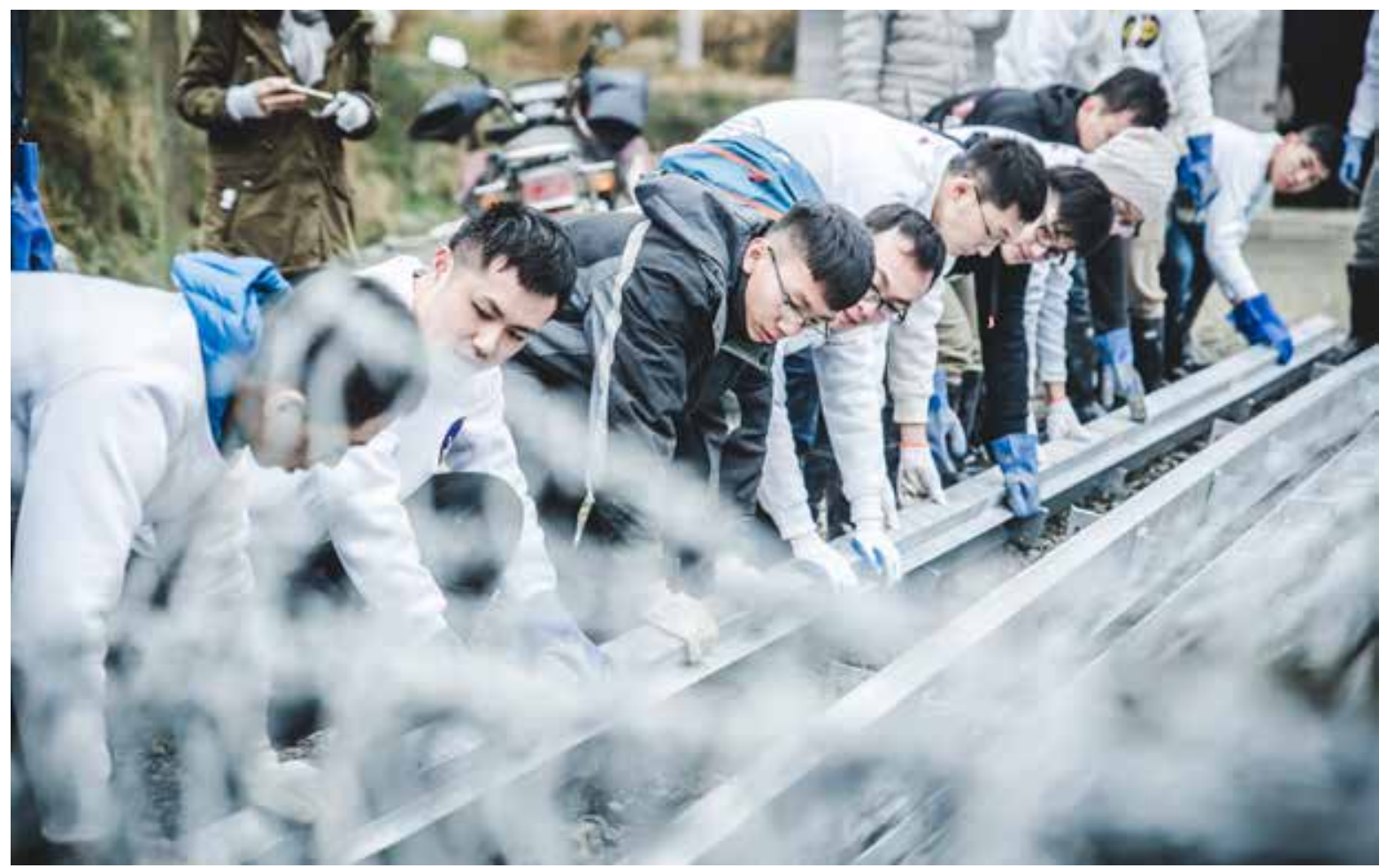

Figures 1-3 (pages 110-112): Feungshan Village, Wu Zhi Qiao (Bridge to China) (2017): Gabion bridge design and build in Feungshan Village, Qianjiang District, Chongqing, China. Source: author. 


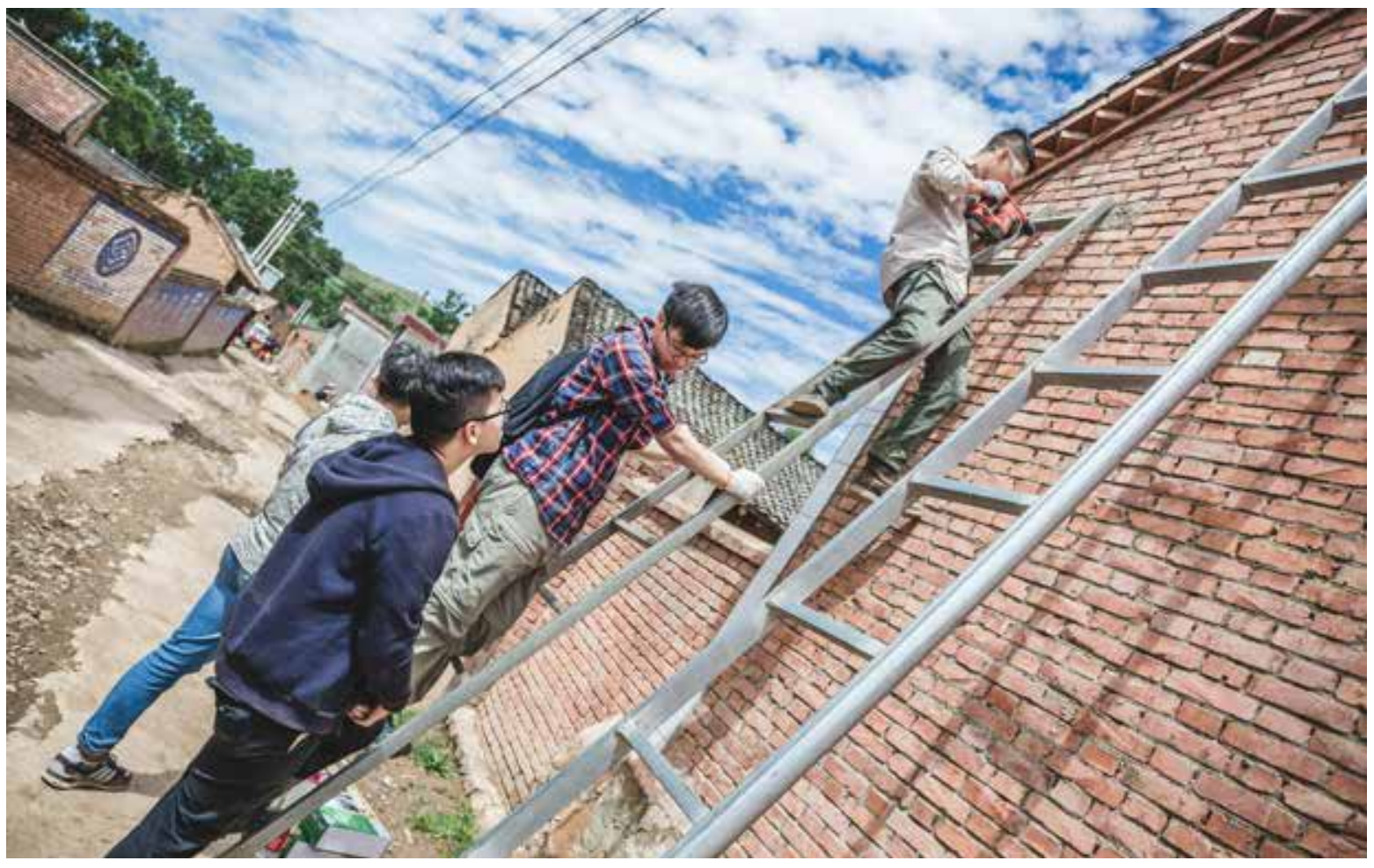

Figures 4-6 (pages 113-117): Light for the village (2017): Installation of solar light panels and village improvement projects in Datan Village, Zhangjia County, Gansu, China. Source: author. 
Haxt wes?

CUBIC JOURNAL - No.4.Pedagogy C Critique - Transformation

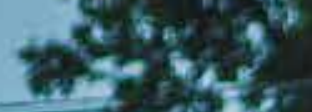

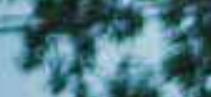 2.tinger}

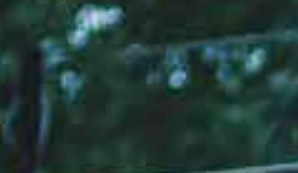

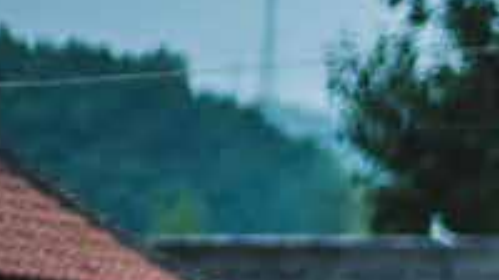

Q

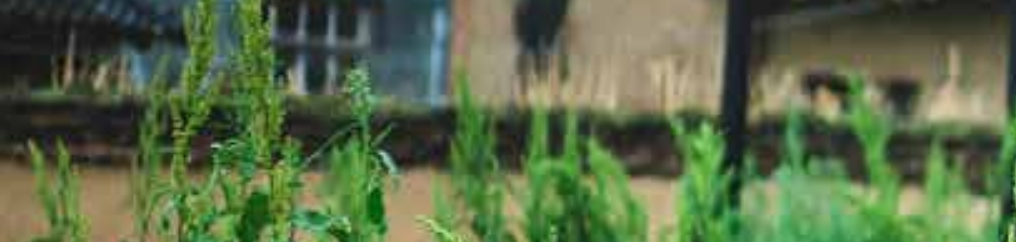

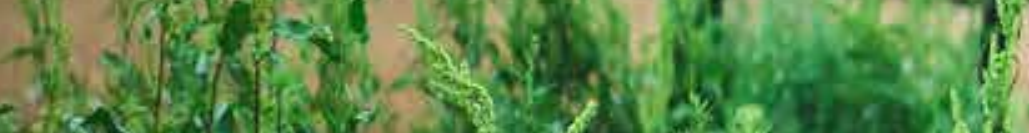
4. .

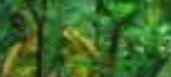
19.5.

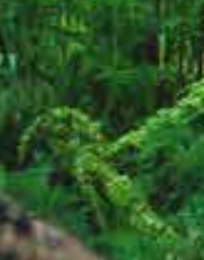

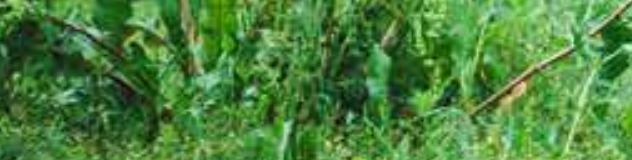
(f) set

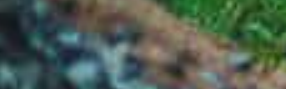

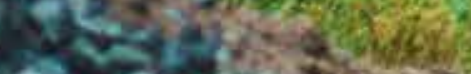

(2) $\left.x^{2}\right)$

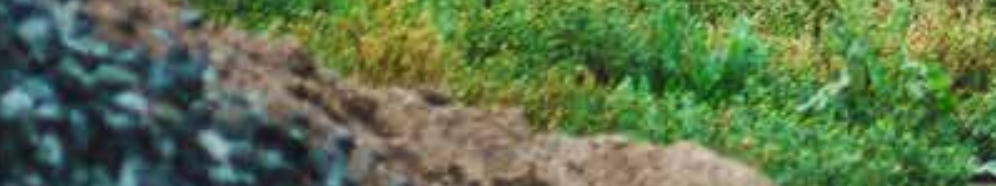

iving if:

A.

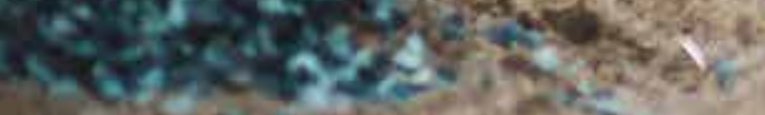

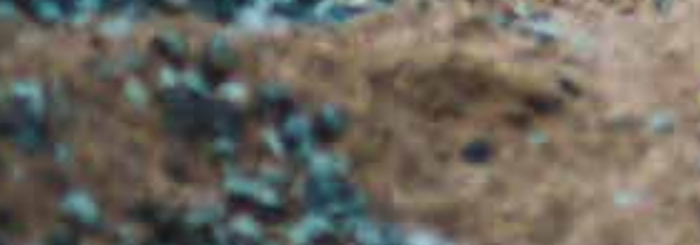

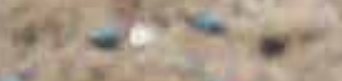

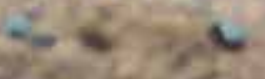

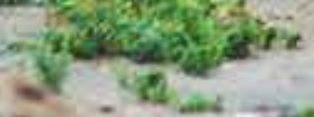
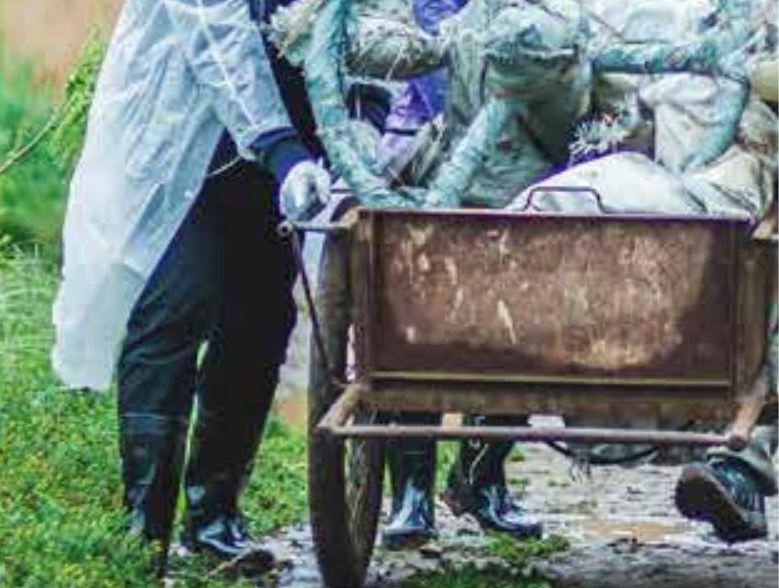

Maristis

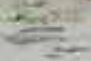

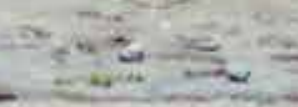

Tos
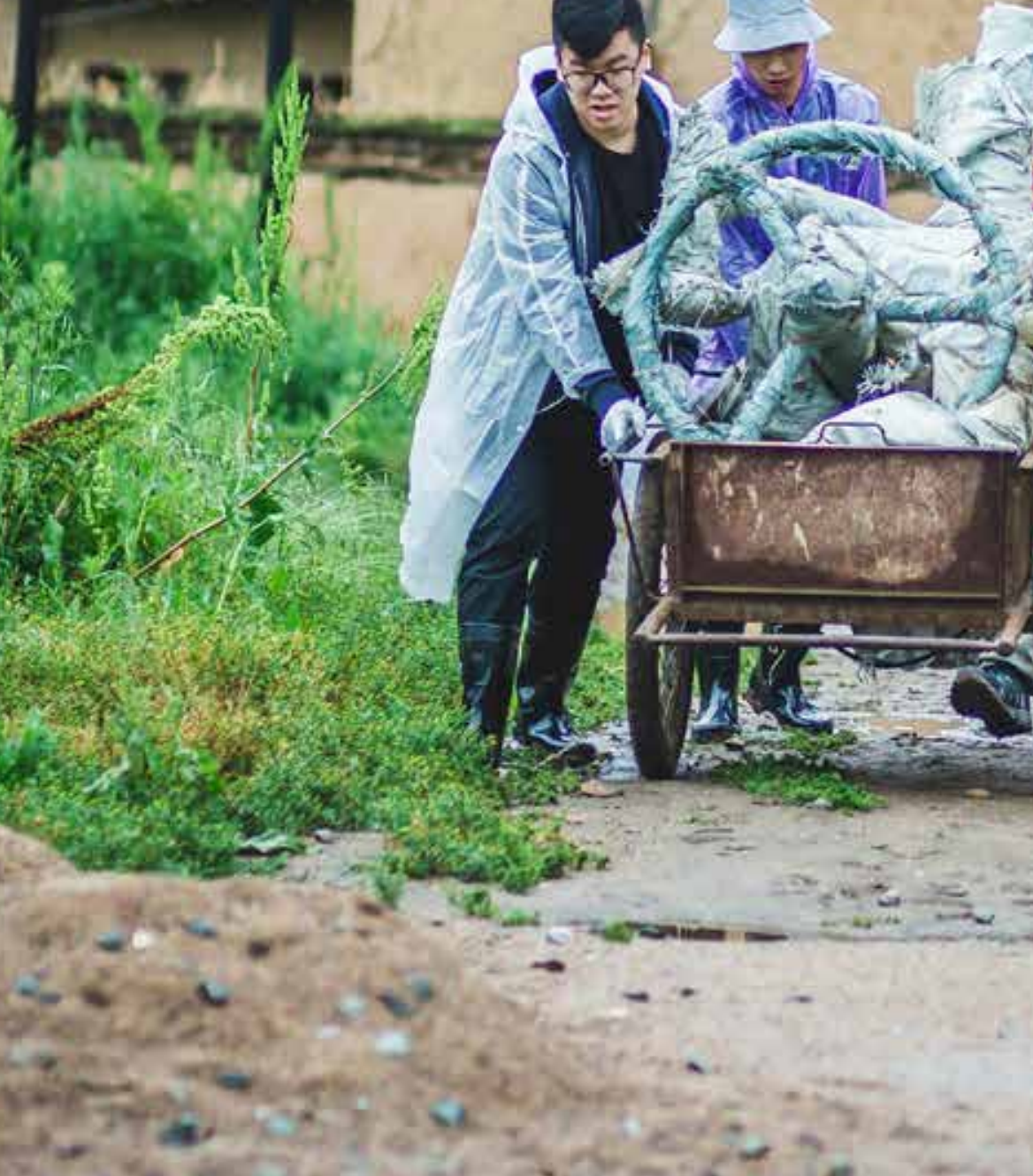

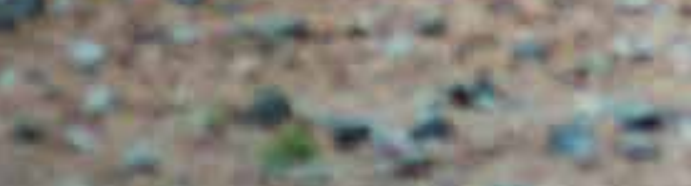

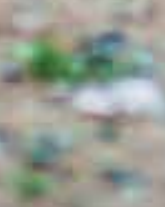$$
\frac{2}{2}
$$$$
x^{2}+2+2+2+2=
$$$$
-
$$ 

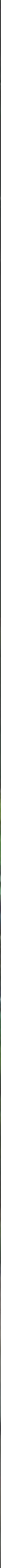
116 |

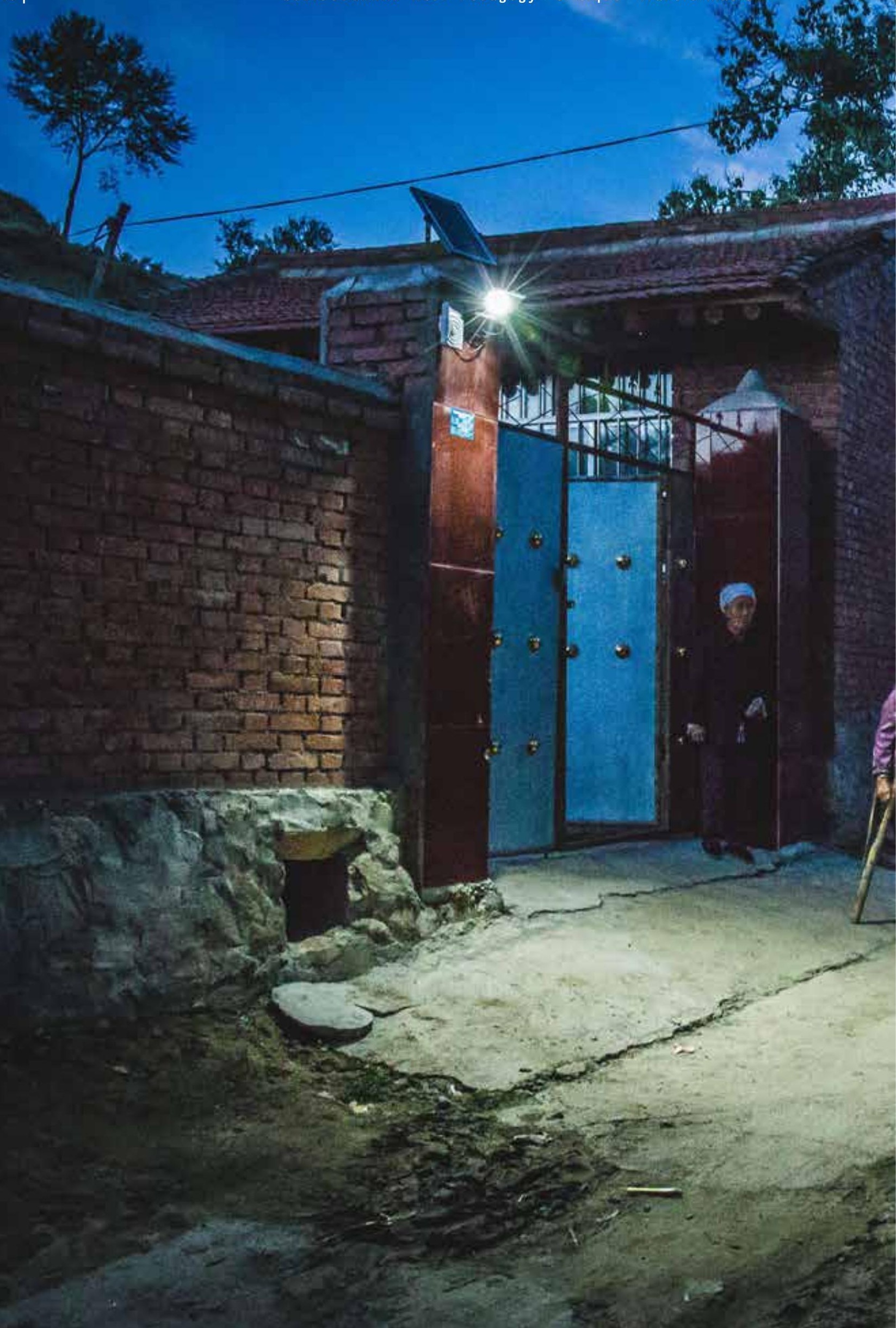




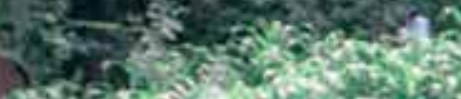

A. 670 (2)

x)

a 5. 512

at: 0.01 $5 x+4$

5

.

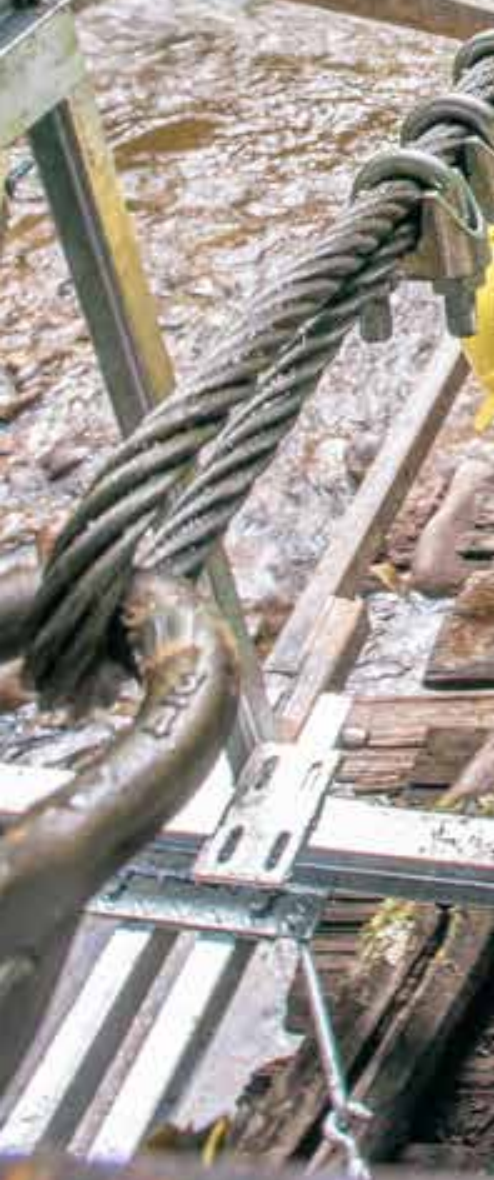

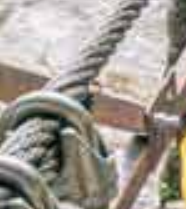



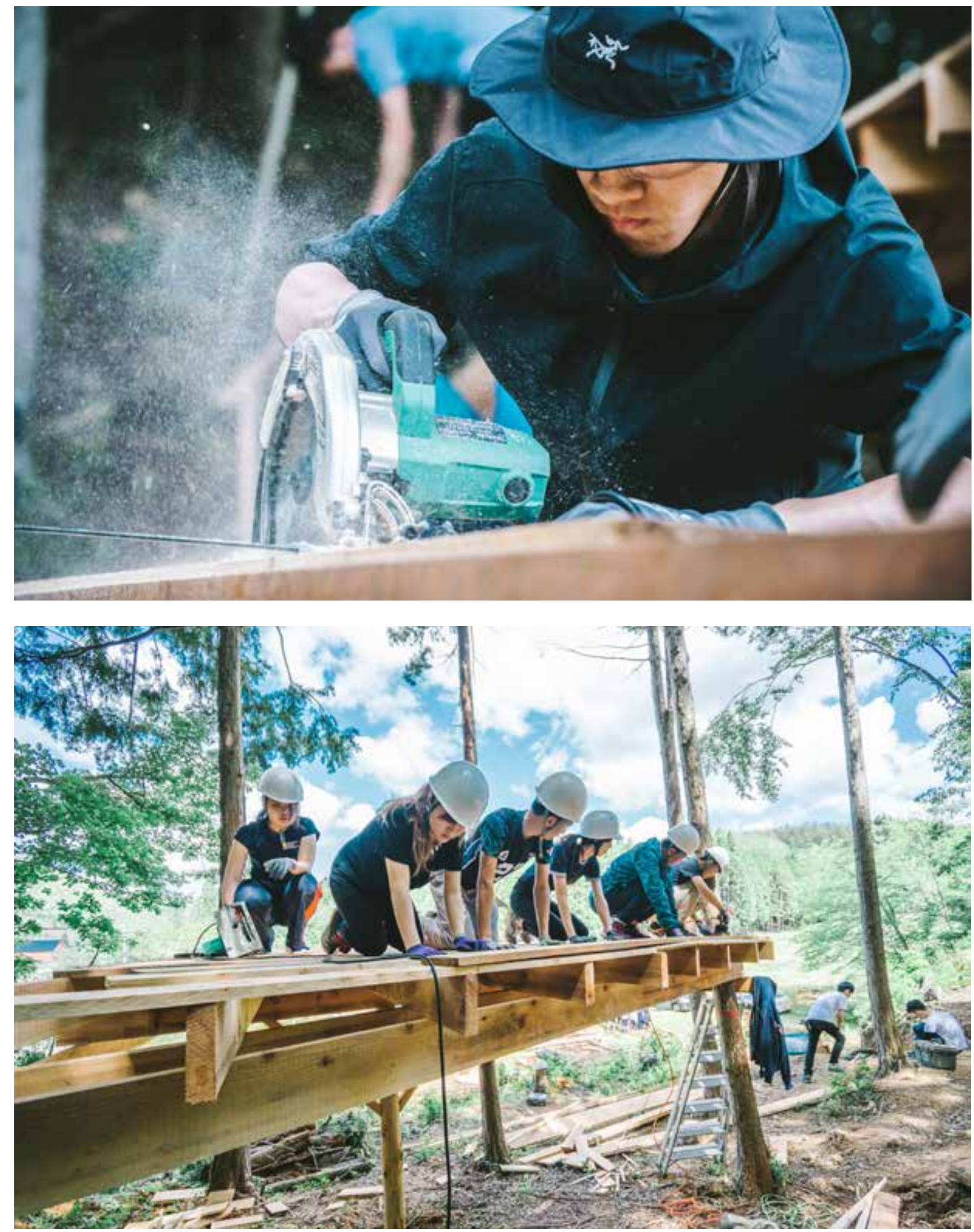

Figure 7 (previous page): WHARF Liming Village Wu Zhi Qiao (2018): Bailey bridge design and build in Liming Village, Lijiang, Yunna, China. Source: author.
Figures 8-10 (this and next page): Design and build for remote community, Japan (2019) Pavilion Design and Build in Keihoku, Japan. Source: author. 


\section{Acknowledgements}

Educational and professional partners have kindly led their support to the service-learning project. From Hong Kong, acknowledgement is given to the institutions of the School of Design, The Hong Kong Polytechnic University, and in particular Professor Edward Ng (The Chinese University of Hong Kong), Sir David Akers-Jones (GBM KBE CMG JP) and Miss Leonie Ki (GBS, SBS, JP), with additional support provided by The Chinese University of Hong Kong, The Hong Kong University of Science and Technology and Chuhai College. Mainland Universities include Tsinghua University, Tonji University, Sichuan University, Chongqing University, Chongqing Jiaotong University, Xi'an Jiaotong University, Xi'an University of Architecture Technology and Kunming University of Science and Technology with Edinburgh University (UK) and Kyoto University (Japan) as international partners. Further project support was provided by the Ministry of Housing and Urban-Rural Development (MoHURD)(China), further supported by local Chinese government which include Chongqing, Gansu, Guizhou, Guanxi, Yunnan, and Shannxi. Japanese government support provided by the Kyoto prefecture, Nara and Shiga prefectures, further supported by industry partners Roots Inc. in Keihoku, Japan.

\section{Bio}

Michael Chan is a senior teaching fellow of the School of Design, The Hong Kong Polytechnic University. He is an architect who is active in a range of design-build projects, amongst whch are the Eco-bridge education project in Shannxi, Gansu, Sichuan, Guizhou and Guangxi providences in mainland China spanning more than 15 years. He was a member of the School of Design's Service-Learning Task Force, Service-Learning subcommittee and the School of Hotel and Tourism Management School Board, judging panel of Hong Kong Scholarship for Excellence Scheme (HKSAR), and the vice chairman of HKDSE Applied Subject Committee (HKSAR). In addition, he serves as member of the Management Council of the Wu Zhi Qiao (Bridge to China) Charitable Foundation and project leader of the WZQ service-learning programme. He is recipient of the 2020 Faculty Award for Outstanding Education Achievements. 